BMJ Open Sport \& Exercise Medicine

\title{
Do rugby league players under-report concussion symptoms? A cross-sectional study of elite teams based in Australia
}

\author{
Thomas Longworth, ${ }^{1,2}$ Andrew McDonald, ${ }^{2}$ Corey Cunningham, ${ }^{3}$ Hussain Khan, ${ }^{4}$ \\ Jane Fitzpatrick (D) 5,6
}

To cite: Longworth T, McDonald A, Cunningham C, et al. Do rugby league players under-report concussion symptoms? A cross-sectional study of elite teams based in Australia. BMJ Open Sport \& Exercise Medicine 2021;7:e000860. doi:10.1136/ bmjsem-2020-000860

Accepted 6 January 2021

Check for updates

\section{(C) Author(s) (or their} employer(s)) 2021. Re-use permitted under CC BY-NC. No commercial re-use. See rights and permissions. Published by BMJ.

${ }^{1}$ Registrar, Australasian College of Sport and Exercise Physicians, Melbourne, Victoria, Australia

${ }^{2}$ Sports Medicine, Eastern Suburbs Sports Medicine Centre, Sydney, New South Wales, Australia

${ }^{3}$ Medical, New South Wales Institute of Sport, Sydney Olympic Park, New South Wales, Australia

${ }^{4}$ Sports Medicine, Olympic Park Sports Medicine Centre, Melbourne, Victoria, Australia ${ }^{5}$ Centre for Health and Exercise Sports Medicine, The University of Melbourne Faculty of Medicine Dentistry and Health Sciences, Melbourne, Victoria, Australia

${ }^{6}$ Research Committee, Australasian College of Sport and Exercise Physicians, Melbourne, Victoria, Australia

Correspondence to Dr Jane Fitzpatrick; jane.fitzpatrick@unimelb.edu.au

\section{ABSTRACT}

Objective To determine the rate of under-reporting of concussion and its symptoms in elite rugby league players in Australia.

Methods The study was conducted in the preseason of the 2020 National Rugby League (NRL) competition. A total of 151 male, NRL club contracted rugby league players across three professional clubs participated. The participants completed a voluntary, anonymous survey exploring player demographics, concussion data, underreporting instances and reasons for under-reporting over the 2018 and 2019 rugby league seasons.

Results $17.2 \%$ of surveyed players reported sustaining a likely concussion over the past 2 years and not reporting to medical staff. $22 \%$ of NRL first grade players admitted to not reporting at least one concussion during the 2018 and 2019 seasons. The most common reason not to report was the player 'not wanting to be ruled out of the game or training session' (57.7\%), followed by 'not wanting to let down the coaches or teammates' (23.1\%). $85.4 \%$ of surveyed players reported having concussion education by their club in the previous two seasons.

Conclusions $17.2 \%$ of elite rugby league players in Australia chose not to report likely concussive episodes and concussion-related symptoms during the 2018 and 2019 seasons. Clinicians need to be aware of underreporting in athletes when assessing players following head injuries. The findings highlight the need for development of validated, objective testing for concussion following sports-associated head injury.

\section{INTRODUCTION}

In many contact sports, there is suspicion of under-reporting by athletes of concussion and its symptoms. ${ }^{1-3}$ The under-reporting of concussion symptoms may lead to missed concussion diagnosis and a subsequent increase in short-term or long-term injury for the affected sportspeople. ${ }^{14}$ Rugby League has high rates of concussive injury, with the National Rugby League (NRL) competition recording 102 concussions in games during the 2019 season equating to 14.7 per 1000 playing hours. ${ }^{5}$ The diagnosis of concussion is reliant on the SCAT5 sideline assessment combined with the witnessed on-field incident

\section{What are the new findings?}

- The study highlights the under-reporting rates for concussive injury in elite rugby league, with $17.2 \%$ of players surveyed admitting to at least one instance of under-reporting in the past two seasons.

- The majority of reasons given by players for misreporting are due to their desires to not miss game time or training sessions.

How might this study impact clinical practice in the future?

- Improved team physician awareness of underreporting will increase suspicion of concussive injury despite the lack of player-reported symptoms.

- The awareness of under-reporting of concussion symptoms further highlights the need to develop a validated, objective tool to assist in sideline concussion diagnosis for clinicians.

and the clinical skills of the team doctor. ${ }^{1}$ The player-reported symptom load is an important tool in assisting the clinician in making the diagnosis of concussion. ${ }^{14}$

There is good epidemiological data on concussion rates from other contact sports that can be compared with rugby league. For example, the Irish professional Rugby Union competition (2017 season) and Australian Football League (2015 season) report 18.4 concussions per 1000 playing hours and 6 concussions per 1000 playing hours, respectively. ${ }^{6} 7$ The research surrounding symptom reporting bias and the reluctance of players to report concussion symptoms is more scarce. Of the available data, there appears to be a high rate of under-reporting across a range of contact sports, with research highlighting between $19.6 \%$ and $82.1 \%$ of under-reporting of concussive episodes in athletes. ${ }^{2-13}$ The highest rate of under-reporting was found in a cohort of Canadian Football players (gridiron) and the lowest in professional race 
jockeys. It is most likely that under-reporting of concussive episodes and symptoms also occurs in elite rugby league, based on the research performed in other contact sports.

There is currently no research available to determine the rates of under-reporting of concussion symptoms in rugby league in Australia, or overseas. Our study aims to determine the rates of under-reporting in elite rugby league and explore the reasons why players may not report symptoms or suspected concussions. The results of this study may help expose the current flaws in concussion diagnosis based on subjective symptom reporting, as well as direct future player education based on the reasons for under-reporting.

\section{METHODS}

The NRL is an Australian and New Zealand professional rugby league competition played over 25 rounds from March to October each year. There are 16 professional teams ( 15 based in Australia and 1 in New Zealand). Each team has 36 contracted senior men's players as well as variable numbers of players aged under 20 years.

\section{Patient and public involvement statement}

Participants were introduced to the survey by various club staff and the aims of the study were described to all consenting players. There was no direct participant or public feedback that altered the study design. The time burden on the participants was minimal in all cases. The results will be disseminated across all participating clubs by the club doctors involved in the study.

\section{Study sample and data extraction}

Players from three of the NRL clubs were selected to participate in a voluntary, anonymous survey (online supplemental appendix A) on player behaviour surrounding concussion reporting and reasons for under-reporting over the 2018 and 2019 Australian rugby league seasons. Three NRL clubs were approached, two in New South Wales and one in Queensland, as a cross-sectional representation of the entire NRL. An estimated 90 open age contracted players and 100 under 20s contracted players were asked to participate in the survey by their respective club doctors/physiotherapists or sports trainers. The numbers are estimated based on usual squad sizes at each club, but numbers may have had slight variation depending on daily player attendances when the survey was distributed. The surveys were distributed during the 2020 preseason and collected by the club representative who was instructed not to review the answers or identify players, the reason for this was to reduce the risk of reporting bias. The completed hard copy survey forms were sent or delivered to the author (TL) between January and March 2020.

\section{The survey}

An anonymous retrospective survey was used to allow players to report instances of under-reporting without the fear of being sidelined or reducing chance of future team selection. Similar surveys have been used in studies investigating concussion reporting in Canada and Ireland and appear to reduce reporting bias in athletic cohorts. $^{211}$ The survey was created to be completed in a short amount of time with direct questioning to improve compliance and response rates.

The questionnaire consisted of nine questions and was estimated to take 3-5 min to complete. The questions addressed player demographics including age range, years playing elite rugby league, usual position and number of concussions diagnosed in the past two seasons. Specific questions explored instances of concussion that were not reported, misreporting of symptoms during concussion assessments and the reasons for any misreporting. The players were asked if they had had intraclub education surrounding concussion and the potential consequences of under-reporting.

\section{Analysis}

All data were collated in a spreadsheet (Microsoft Excel, USA) and all analyses were undertaken using Stata V.13.0 for Mac (StataCorp). Players were divided into three main categories according to the level they played at the time of study; NRL, reserve grade and under 20 players. Simple descriptive analyses were used to describe baseline characteristics.

Main outcome measures were the number of concussions diagnosed in the last 2 years, number of players who did or did not report a concussion, number of players who did or did not report correct symptoms during subsequent assessment after a concussion was diagnosed, when players under-reported and reasons for doing so.

Univariable analyses using logistic regression were used to the examine the associations between under-reporting of concussion symptoms during recovery and predictor variables such age, concussion education, years played, current level and history of concussions in the past. Fisher's exact test was performed as a test of independence to examine the association between players not reporting symptoms and reasons for under-reporting. Values of $\mathrm{p}<0.05$ were considered statistically significant.

\section{Patient and public involvement}

Patients and/or the public were involved in the design, or conduct, or reporting, or dissemination plans of this research. Refer to the 'Methods' section for further details.

\section{RESULTS}

\section{Participants demographics}

Across the three NRL clubs there were a total of 151 players responses, this comprised 59 players who identified as a first grade player $(39.1 \%), 32$ players who identified as a reserve grade player $(21.2 \%)$ and 60 players who identified as an under 20 years player $(39.7 \%)$ (see table 1 ). Based on 36 contracted NRL players per club this equates to a response rate of $84.3 \%$, inclusive of both players who identify as NRL or reserve grade players. The under 20 
Table 1 Age range, years of playing experience in elite competition and exposure to concussion education reported by elite rugby league participants in Australia

\begin{tabular}{|c|c|c|c|c|c|}
\hline & & $\begin{array}{l}\text { Total } \\
(n=151)\end{array}$ & $\begin{array}{l}\text { NRL } \\
(n=59)\end{array}$ & $\begin{array}{l}\text { Reserve grade } \\
(n=32)\end{array}$ & $\begin{array}{l}\text { U20s } \\
(n=60)\end{array}$ \\
\hline \multirow{6}{*}{ Age range (years) } & $<18$ & 22 (14.6\%) & $1(1.7 \%)$ & $0(0 \%)$ & 21 (35\%) \\
\hline & $19-22$ & 75 (49.7\%) & 15 (25.4\%) & $21(65.6 \%)$ & $39(65 \%)$ \\
\hline & $23-25$ & $21(13.9 \%)$ & $13(22 \%)$ & $8(25 \%)$ & $0(0 \%)$ \\
\hline & $26-28$ & $14(9.3 \%)$ & $12(20.3 \%)$ & 2 (6.3\%) & $0(0 \%)$ \\
\hline & $29-30$ & $11(7.3 \%)$ & $10(16.9 \%)$ & $1(3.1 \%)$ & $0(0 \%)$ \\
\hline & $>30$ & $8(5.3 \%)$ & $8(13.6 \%)$ & $0(0 \%)$ & $0(0 \%)$ \\
\hline \multirow{3}{*}{$\begin{array}{l}\text { Years played in elite } \\
\text { competitions }\end{array}$} & $0-2$ & $67(44.4 \%)$ & $5(8.5 \%)$ & $8(25 \%)$ & 54 (90\%) \\
\hline & $3-5$ & $29(19.2 \%)$ & $13(22 \%)$ & $11(34.4 \%)$ & $5(8.3 \%)$ \\
\hline & $>5$ & $55(36.4 \%)$ & $41(69.5 \%)$ & $13(40.6 \%)$ & $1(1.7 \%)$ \\
\hline \multirow{3}{*}{$\begin{array}{l}\text { Concussion education } \\
\text { by the club }\end{array}$} & Yes & $129(85.4 \%)$ & $53(89.8 \%)$ & $28(87.5 \%)$ & $48(80 \%)$ \\
\hline & No & $6(4 \%)$ & $1(1.7 \%)$ & $1(3.1 \%)$ & $4(6.7 \%)$ \\
\hline & Unsure & $16(10.6 \%)$ & $5(8.5 \%)$ & $3(9.4 \%)$ & $8(13.3 \%)$ \\
\hline
\end{tabular}

$\%$, percentage of participants in subsection; n, number of participants; NRL, National Rugby League.

years players response rate is an estimate as clubs contract differing numbers of players. Table 1 outlines the demographics of the survey group, including age range, years playing in the elite competitions and exposure to concussion education. As expected, the NRL group were much more experienced in regard to years played in elite competitions, and had better reported exposure to concussion education (90\% reported having education, $8.5 \%$ unsure and $1.5 \%$ denied having education).

\section{Concussion episodes}

Table 2 outlines the reporting behaviours of the participants. Across the total group, concussion incidence was high for the past two seasons; $55.7 \%$ of players reported at least one diagnosed concussion in the past 2 years. This was increased to $67.2 \%$ when looking at the NRL group only and lower in the under 20 s age group with $40.7 \%$.

\section{Concussion reporting}

A total of 26 athletes $(17.2 \%)$ reported having a likely concussion in the past two seasons and not reporting it to a staff member or doctor (see table 2). This is $31.3 \%$ of players that reported having at least one diagnosed concussion over the 2018/19 seasons; $16.8 \%$ of surveyed players marked they had intentionally not reported a symptom during a concussion assessment with the team doctor. Table 2 outlines the reporting behaviours of the participants.

Table 3 outlines the reasons for under-reporting of symptoms. More than half of the participants $(57.7 \%)$

\begin{tabular}{|c|c|c|c|c|c|}
\hline & & Total & NRL & Reserve grade & U20s \\
\hline \multicolumn{2}{|c|}{$\begin{array}{l}\text { No. of players diagnosed with concussion in the past } 2 \\
\text { years }\end{array}$} & $\begin{array}{l}83 / 149 \\
(55.7 \%)\end{array}$ & $\begin{array}{l}39 / 58^{*} \\
(67.2 \%)\end{array}$ & $\begin{array}{l}20 / 32 \\
(62.5 \%)\end{array}$ & $\begin{array}{l}24 / 59^{*} \\
(40.7 \%)\end{array}$ \\
\hline \multicolumn{2}{|c|}{$\begin{array}{l}\text { No. of players who always reported a suspected } \\
\text { concussion }\end{array}$} & $\begin{array}{l}125 \\
(83.9 \%)\end{array}$ & $\begin{array}{l}46 \\
(78.0 \%)\end{array}$ & $\begin{array}{l}26 \\
(81.2 \%)\end{array}$ & $\begin{array}{l}53 \\
(88.3 \%)\end{array}$ \\
\hline \multirow[t]{3}{*}{$\begin{array}{l}\text { Players who did not report } \\
\text { a likely concussion }\end{array}$} & 12 occasions & $\begin{array}{l}23 \\
(15.4 \%)\end{array}$ & $\begin{array}{l}11 \\
(18.6 \%)\end{array}$ & $\begin{array}{l}6 \\
(18.8 \%)\end{array}$ & $\begin{array}{l}6 \\
(10.0 \%)\end{array}$ \\
\hline & 3-5 occasions & $\begin{array}{l}2 \\
(1.3 \%)\end{array}$ & $\begin{array}{l}2 \\
(3.4 \%)\end{array}$ & $\begin{array}{l}0 \\
(0.0 \%)\end{array}$ & $\begin{array}{l}0 \\
(0.0 \%)\end{array}$ \\
\hline & $5+$ occasions & $\begin{array}{l}1 \\
(0.7 \%)\end{array}$ & $\begin{array}{l}0 \\
(0.0 \%)\end{array}$ & $\begin{array}{l}0 \\
(0.0 \%)\end{array}$ & $\begin{array}{l}1 \\
(1.7 \%)\end{array}$ \\
\hline \multicolumn{2}{|c|}{$\begin{array}{l}\text { No. of players who always reported symptoms on } \\
\text { assessment }\end{array}$} & $\begin{array}{l}126 \\
(84.6 \%)\end{array}$ & $\begin{array}{l}46 \\
(78 \%)\end{array}$ & $\begin{array}{l}28 \\
(88 \%)\end{array}$ & $\begin{array}{l}52 \\
(87 \%)\end{array}$ \\
\hline \multicolumn{2}{|c|}{$\begin{array}{l}\text { No. of players who did not report symptoms on } \\
\text { assessment }\end{array}$} & $\begin{array}{l}25 \\
(16.8 \%)\end{array}$ & $\begin{array}{l}13 \\
(22 \%)\end{array}$ & $\begin{array}{l}4 \\
(12 \%)\end{array}$ & $\begin{array}{l}8 \\
(13 \%)\end{array}$ \\
\hline
\end{tabular}

${ }^{*}$ Two players did not answer this survey question (one from the NRL group, one from the U20s group).

NRL, National Rugby League. 
Table 3 Reported reasons for under-reporting of symptoms of concussion in elite rugby league players in Australia

\begin{tabular}{|c|c|}
\hline Reasons for under-reporting & $\mathrm{N}(\%)$ \\
\hline Always reported & $125(82.8 \%)$ \\
\hline $\begin{array}{l}\text { Despite symptoms, did not think they were } \\
\text { significant }\end{array}$ & $3(2.0 \%)$ \\
\hline $\begin{array}{l}\text { Did not want to be ruled out of training or } \\
\text { game }\end{array}$ & $15(9.9 \%)$ \\
\hline Did not want to let down coaches or team & $6(4.0 \%)$ \\
\hline $\begin{array}{l}\text { Did not think symptoms were related to } \\
\text { concussion }\end{array}$ & $2(1.3 \%)$ \\
\hline
\end{tabular}

reported they did not report a symptom as they did not want to be ruled out of the game or training session. Nearly a quarter of participants $(23.1 \%)$ reported that they did not want to let down the coaches or teammates. Interestingly, no players reported that the under-reporting reason to be fear of future selections or contracts based on the diagnosis. Fisher's exact test was used to examine the association between players under-reporting symptoms and reasons for under-reporting and showed a significant association between the two variables $(p<0.001)$.

Figure 1 shows the timing of under-reporting of symptoms. The majority of under-reporting occurred during or after a game $(56 \%)$.

\section{Trends}

Further analysis performed did not identify any statistically significant associations between age of players, years played, level played and under-reporting of concussion symptoms. However, there was a trend suggesting that players who had reported at least one diagnosed concussion in the past two seasons, were less likely to report a concussion to medical staff (OR 2.5). However, this analysis did not reach statistical significance $(\mathrm{p}=0.055)$. There was also a trend with more playing experience ( $>5$ years in elite competitions) and higher odds of not reporting a likely concussion (OR 1.97, $\mathrm{p}=0.615$ ).

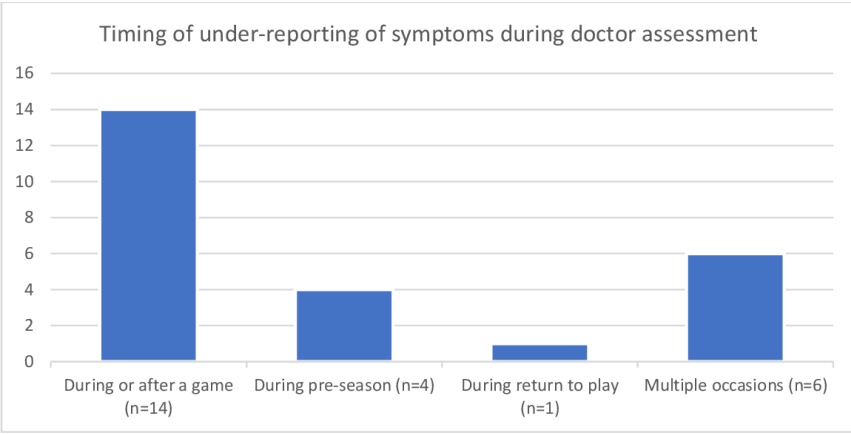

Figure 1 The timing of under-reporting of symptoms. The majority of under-reporting occurred during or after a game (56\%).

\section{DISCUSSION}

Traumatic head injuries and concussion diagnoses are very common in rugby league with the majority $(83 / 149)$ of players in our study reporting at least one concussion in the past two seasons. The diagnosis of a concussion remains dependent on player-reported symptoms, in combination with visualised signs and basic cognitive assessments in comparisons with baselines. ${ }^{14}$ The current study reveals that a significant percentage $(22 \%)$ of NRL players still, at times, choose to conceal concussion symptoms during a doctor-led concussion assessment, which may result in missed or delayed diagnosis of concussion.

\section{Rates of under-reporting}

An encouraging finding in the current study is the perceived reduction of under-reporting when compared with similar studies done across other sports. At $17.2 \%$ this is the lowest under-reporting rate noted in published studies we have found during the literature review. ${ }^{28-13}$ The very high reported rates of club led concussion education may reflect in this improved rate of player reporting. $85.4 \%$ of players surveyed reported having annual education on concussion and its potential consequences. It remains unknown if the rate of under-reporting in rugby league has reduced, as this is the first known study of its type. Future research may identify trends of concussion reporting, the author would expect an improvement as education and long-term implications become more apparent. The increasing media coverage of concussion and the reducing stigma around reporting may be a reason for the improved reporting rates in our study when compared with other sports in other countries. ${ }^{14}$

\section{Reasons for under-reporting}

The majority of reasons for under-reporting in our study were related to either; not wanting to be ruled out of the game or training, or, not wanting to let down coaches or the team. These answers may highlight the good knowledge of concussion symptoms in players and the tendency to not report due to the known repercussions. These interpersonal reasons were found to be a common reason of under-reporting by Corman et al, ${ }^{3}$ who investigated National Collegiate Athletic Association athletes reporting behaviours. It appears that players in the higher grade (NRL) have a greater tendency to not report concussion symptoms compared with under 20 years players (22\% vs $13 \%$ ). The authors consider this is likely related to the greater pressures on the higher grade players from coaches, teammates and the public. An increase in external pressures on a player has been shown to increase the likelihood of a player continuing in a game despite symptoms of concussion. ${ }^{15-17}$

The reasons for under-reporting can help direct future education for players across elite competitions. ${ }^{18}$ Education focussing on the personal repercussions of under-reporting concussion symptoms and the potential short-term and long-term implications of playing on with concussion may help with player behaviour change. ${ }^{18} 19$ 
The tendency for players to misreport during or after a game $(56 \%)$, again supports that pressure of match play and expectations are implicated in the under -reporting in these situations.

\section{Future directives}

The evidence that under-reporting of concussion symptoms is prevalent in elite rugby league is important in highlighting the need for a more objective sideline diagnostic tool for concussive injury. Despite players having annual education on the topic of concussion, the underreporting of symptoms appears to be driven by the desire to continue playing or not to let the team down, rather than due to inadequate knowledge of the symptoms or consequences of concussion. It is likely that as long as player-reported symptoms are a significant part of the concussion assessment then a number of concussive injuries will be missed due to player under-reporting. The introduction of match day video review, independent 'spotters' and increased medical presence at games is designed to improve concussion identification rates. ${ }^{20}$ The number of players removed from the field due to identification of signs of concussion, who otherwise would not have reported concussive symptoms, is unknown.

This study creates a reference point for further contact sport research into the reporting attitudes of players around concussive injury. Further research in the area would be encouraged with a larger cohort and with comparisons against sporting organisation concussion data, to help identify the true gap between concussions suffered and concussions identified by medical staff. The overall goal is to achieve an improved rate of concussion identification and subsequent improved player health outcomes.

\section{Limitations}

It is difficult to ascertain the accuracy of the study in regard to reporting bias. The use of anonymous surveys performed by players on a voluntary basis attempts to minimise the chance of bias. The high response rate in our cohort and similar reporting rates across the different grades is supportive of an unbiased snapshot of the rates of under-reporting in elite rugby league. Further research in the area and correlation with NRL documented cases of concussion would be a further area of interest.

The reliability of the survey was not analysed by the authors. Any internal inconsistencies in answering the questions cannot be ruled out and is recognised as a limitation of the study.

The current study selected three NRL clubs to participate in the survey, with good response rates. Extension of the survey across all 16 clubs would be necessary to get a more accurate idea of reporting rates in the NRL. This initial study will hopefully encourage more professional teams to take notice of potential under-reporting and participate in a competition wide research project.

\section{CONCLUSION}

The research identified $17.2 \%$ of elite rugby league players in Australia chose not to report likely concussive episodes and concussion-related symptoms during the 2018 and 2019 seasons. Clinicians need to be aware of under-reporting in athletes when assessing players following head injuries. The findings highlight the need for development of validated, objective testing for concussion following sports associated head injury.

\section{Twitter Jane Fitzpatrick @sportsdocaus}

Acknowledgements The authors would like to thank the team physicians and medical staff at the NRL clubs for facilitating the survey distribution and collection at their respective clubs and the National Rugby League research committee for endorsing the project.

Contributors All authors made substantial contributions to the conception or design of the work, or the acquisition, analysis or interpretation of data, drafting the work or revising it critically for important intellectual content. TL wrote the first draft of this work. All authors gave final approval of the version published and have had free access to data related to the study. The authors agree to be accountable for all aspects of the work in ensuring that questions related to the accuracy or integrity of any part of the work are appropriately investigated and resolved.

Funding The authors have not declared a specific grant for this research from any funding agency in the public, commercial or not-for-profit sectors.

Competing interests TL and AMcD are contracted doctors for NRL clubs.

Patient consent for publication Not required.

Ethics approval This project had ethics approval granted on 12 November 2019 by the Australian Institute of Sport Ethics Committee (project number: 20191105). The project was endorsed by The Rugby League Research Committee.

Provenance and peer review Not commissioned; externally peer reviewed.

Data availability statement All data relevant to the study are included in the article or uploaded as supplementary information. All data from this study are included in the manuscript.

Open access This is an open access article distributed in accordance with the Creative Commons Attribution Non Commercial (CC BY-NC 4.0) license, which permits others to distribute, remix, adapt, build upon this work non-commercially, and license their derivative works on different terms, provided the original work is properly cited, appropriate credit is given, any changes made indicated, and the use is non-commercial. See: http://creativecommons.org/licenses/by-nc/4.0/.

\section{ORCID iD}

Jane Fitzpatrick http://orcid.org/0000-0002-9578-026X

\section{REFERENCES}

1 McCrory P, Meeuwisse W, Dvořák J, et al. Consensus statement on concussion in sport-the $5^{\text {th }}$ international conference on concussion in sport held in Berlin, October 2016. Br J Sports Med 2017;51:838-47.

2 Delaney JS, Caron JG, Correa JA, et al. Why professional football players chose not to reveal their concussion symptoms during a practice or game. Clin J Sport Med 2018;28:1-12.

3 Corman SR, Adame BJ, Tsai J-Y, et al. Socioecological influences on concussion reporting by NCAA division 1 athletes in high-risk sports. PLoS One 2019;14:e0215424.

4 Harmon KG, Clugston JR, Dec K, et al. American medical Society for sports medicine position statement on concussion in sport. Br J Sports Med 2019;53:213-25.

5 O'Connor D. NRL injury surveillance report 2019 season. rugby League research Committee, 2020.

6 Cosgrave M, Williams S. The epidemiology of concussion in professional rugby union in Ireland. Phys Ther Sport 2019;35:99-105.

7 Saw R, Finch CF, Samra D, et al. Injuries in Australian rules football: an overview of injury rates, patterns, and mechanisms across all levels of play. Sports Health 2018;10:208-16.

8 O'Connor S, Warrington G, Whelan G, et al. Concussion history, reporting behaviors, attitudes, and knowledge in Jockeys. Clin J Sport Med 2020;30:578-84. 
9 Register-Mihalik JK, Guskiewicz KM, McLeod TCV, et al. Knowledge, attitude, and concussion-reporting behaviors among high school athletes: a preliminary study. J Athl Train 2013;48:645-53.

10 Williamson IJS, Goodman D. Converging evidence for the underreporting of concussions in youth ice hockey. Br J Sports Med 2006;40:128-32.

11 Fraas MR, Coughlan GF, Hart EC, et al. Concussion history and reporting rates in elite Irish rugby union players. Phys Ther Sport 2014;15:136-42.

12 Meehan WP, Mannix RC, O'Brien MJ, et al. The prevalence of undiagnosed concussions in athletes. Clin J Sport Med 2013;23:339-42.

13 Kroshus E, Kubzansky LD, Goldman RE, et al. Norms, athletic identity, and concussion symptom under-reporting among male collegiate ice hockey players: a prospective cohort study. Ann Behav Med 2015;49:95-103.

14 Kerr ZY, Register-Mihalik JK, Marshall SW, et al. Disclosure and non-disclosure of concussion and concussion symptoms in athletes: review and application of the socio-ecological framework. Brain Inj 2014;28:1009-21.
15 Kroshus E, Garnett B, Hawrilenko M, et al. Concussion underreporting and pressure from coaches, teammates, fans, and parents. Soc Sci Med 2015;134:66-75.

16 Kerr ZY, Marshall SW, Guskiewicz KM. Reliability of concussion history in former professional football players. Med Sci Sports Exerc 2012;44:377-82.

17 Torres DM, Galetta KM, Phillips HW, et al. Sports-related concussion: anonymous survey of a collegiate cohort. Neurol Clin Pract 2013;3:279-87.

18 McCrea M, Hammeke T, Olsen G, et al. Unreported concussion in high school football players: implications for prevention. Clin J Sport Med 2004;14:13-17.

19 Prien A, Grafe A, Rössler R, et al. Epidemiology of head injuries focusing on concussions in team contact sports: a systematic review. Sports Med 2018;48:953-69.

20 Davis GA, Makdissi M, Bloomfield P, et al. International consensus definitions of video signs of concussion in professional sports. $\mathrm{Br} \mathrm{J}$ Sports Med 2019;53:1264-7. 